\title{
Chemokines in vascular pathology (Review)
}

\author{
STAVROS APOSTOLAKIS ${ }^{1}$, EMMANOUIL G. PAPADAKIS ${ }^{2}$, \\ ELIAS KRAMBOVITIS ${ }^{3}$ and DEMETRIOS A. SPANDIDOS ${ }^{1}$ \\ ${ }^{1}$ Laboratory of Clinical Virology, Faculty of Medicine, University of Crete; \\ ${ }^{2}$ Onassis Cardiac Surgery Centre, Athens; ${ }^{3}$ Department of Applied Biochemistry and Immunology, \\ Institute of Molecular Biology and Biotechnology, FORTH, Heraklion, Crete, Greece
}

Received January 31, 2006; Accepted March 1, 2006

\begin{abstract}
Clinical complications of atherosclerosis are major causes of morbidity and mortality in Western societies. Recent evidence suggests that formation of atherosclerotic lesions is an inflammatory process involving multiple molecular pathways. Chemokine-mediated mechanisms are potent regulators of such processes by orchestrating the interactions of inflammatory cellular components of the peripheral blood with cellular components of the arterial wall. The increasing evidence supporting the role of chemokine-pathways in atherosclerosis renders chemokine ligands and their receptors potential therapeutic targets. In the following review, we intend to highlight the special structural and functional features of each chemokine sub-family in respect to their role in atherosclerosis and discuss to what extent such knowledge could be applied in diagnostic, prognostic or therapeutic practices.
\end{abstract}

\section{Contents}

1. Introduction

2. The $\mathrm{CC}$ chemokines and chemokine receptors

3. The CXC chemokines and chemokine receptors

4. The $\mathrm{CX} 3 \mathrm{C}$ chemokine and chemokine receptor

5. The $\mathrm{C}$ chemokines and chemokine receptors

6. Discussion

\section{Introduction}

Atherosclerosis is a complex, multifactorial disease associated with numerous environmental risk factors interacting with the genetic background of the individual. Elevated plasma

Correspondence to: Professor D.A. Spandidos, Laboratory of Clinical Virology, Faculty of Medicine, University of Crete, Greece E-mail: spandidos@spandidos.gr

Key words: chemokines, vascular pathology cholesterol levels, hypertension, diabetes mellitus and smoking are, among others, recognized as major inducers of endothelial damage. Increasing evidence also suggests that atherosclerosis is an inflammatory disease involving accumulation and activation of inflammatory cells onto the vessel wall (1). In fact, the development of atherosclerotic lesions is the outcome of the interaction of multiple cellular populations of the peripheral blood, mainly monocytes and T lymphocytes, with cell components of the arterial wall, mostly endothelial and smooth muscle cells, in response to multifactorial vascular injury. Several pro-inflammatory factors, chemoattractant cytokines (chemokines) and adhesion molecules are essential in orchestrating this process (2).

Atherosclerosis and chronic inflammation. Despite the fact that the exact nature of endothelial damage is currently not clear, it is well established that the endothelium reacts to injury by increased cell surface expression of adhesion molecules $(1,2)$. Circulating leucocytes that roll on the endothelium are trapped by the increased number of adhesion molecules and migrate between endothelial cells, predominantly at sites of disrupted blood flow patterns and increased shear stress. In the intima of the injured endothelium, monocytes differentiate into macrophages, they absorb modified lipoprotein particles and become foam cells. Accumulation of foam cells in the intima results in the formation of "fatty streaks". Fatty streaks are the first atherosclerotic lesions and can be identified even in infants and young children. If the trigger factor remains, the inflammatory process continues and progresses. The initially protective inflammatory response starts to damage the arterial wall. Dysfunctional endothelial cells and activated leukocytes release cytokines, chemokines and growth factors, and promote the migration of smooth muscle cells (SMCs) into the intima of the arterial wall and give rise to the next stage of lesion formation, the intermediate or fibro-fatty lesion. At this stage, the lesion can contain multiple layers of smooth muscle cells, connective tissue, macrophages and $\mathrm{T}$ cells $(1,2)$. Under the effect of pre-disposing factors, remodelling of the vessel wall occurs resulting in advanced lesion formation. Advanced lesions are susceptible to rapture, the pathophysiological background of acute ischemic events.

Chemokine structural and functional characteristics. Chemokines are low molecular weight chemoattractant cytokines 
known to be major regulatory proteins in leukocyte trafficking and activation. They consist of an expanding family of approximately 50 ligands and 20 receptors which are classified into four sub-groups based on the number and structural arrangement of conserved cysteine residues within their amino-terminal polypeptide sequence $(\mathrm{C}, \mathrm{CC}, \mathrm{CXC}$ and CX3C). CXC (or $\alpha$ ) chemokines have a single amino acid separating the two amino-terminal cysteine residues of the protein, while $\mathrm{CC}$ (or $\beta$ ) chemokines have no amino acid separating the amino-terminal cysteines. Fractalkine is the single member of the $\mathrm{CX} 3 \mathrm{C}$ sub-family having three amino acids separating the two amino-terminal cysteine residues. Finally, the latest-discovered lymphotactine (XCL1) and single C motif chemokine 1- $\alpha$ (SCM1- $\alpha$ or XCL2) are the only currently known members of the $\mathrm{C}$ sub-family and lack two of the four conserved cysteines in the mature protein $(3,4,5)$.

Chemokines induce cell activation by binding to specific seven-transmembrane G-protein coupled cell-surface receptors on target cells. Six human CXC chemokine receptors, ten human $\mathrm{CC}$ chemokine receptors, and a single receptor for each of the $\mathrm{CX} 3 \mathrm{C}$ and $\mathrm{C}$ chemokine sub-families have been up to now identified. An unusual characteristic of most chemokine receptors is their high-affinity for multiple ligands. Chemokines interacting with their receptors on the cell surface lead to the generation of an intracellular signal via the G-protein complex, resulting in cell chemotaxis towards the source of the chemokine $(3,4,5)$.

Chemokines are involved in almost every inflammatory response and they play an important role in the pathogenesis of a wide variety of infectious and inflammatory diseases, such as human immunodeficiency virus-1 (HIV-1) infection, respiratory syncytial virus-induced bronchiolitis, asthma, sarcoidosis, rheumatoid arthritis, glomerulonephritis, inflammatory bowel disease, multiple sclerosis, and atherosclerosis $(2,3,6,7)$.

There is increasing interest in recent literature regarding the role of chemokines in atherosclerosis since they are implicated in essential aspects of atherogenesis, such as recruitment of inflammatory cells onto the vessel wall and proliferation of SMCs in atherosclerotic plaques (8). This vital involvement of chemokines in the establishment and progression of athrosclerosis suggests that medically-important chemokines and their receptors could provide novel targets for therapeutic interventions in atherosclerosis-related diseases, such as coronary artery disease, peripheral artery disease and cerebrovascular disease.

The present review attempts to provide recent evidence supporting the role of chemokines in atherosclerosis and discusses how such knowledge could be applied in diagnostic, prognostic and therapeutic practices. We attempt to highlight the special structural and functional features of each chemokine sub-family in relation to their role in atherosclerosis along with in vitro and in vivo derived supporting evidence. Because of this special focus, we restricted our assessment to selected chemokine aspects. It is quite likely, however, that other facets related to chemokines may well play an important role in atherogenesis. The abbreviations, localization, and main functions of the chemokines implicated in atherosclerosis, are summarized in Table I.

\section{The $\mathrm{CC}$ chemokines and chemokine receptors}

The CC chemokines form the largest chemokine sub-family, containing over 25 currently identified ligands and ten receptors (5).

MCP-1 and CC receptor 2. Monocyte chemoattractant protein-1 (MCP-1 or CCL2) has been the leading target of research in the field of experimental atherosclerosis. It is the prototype molecule of the CC class and a strong chemoattractant for monocytes. The presence of MCP-1 in atherosclerotic lesions was first demonstrated in 1991 by in situ hybridisation and has been confirmed since by several studies and different techniques (9). MCP-1 mRNA expression has been detected in endothelial cells, macrophages and vascular SMCs in atherosclerotic arteries $(10,11,12)$. Several experimental models of atherosclerosis, including low density lipoprotein (LDL) receptor and apolipoprotein E knockout (ApoE-/-) mice, have been used to confirm the role of MCP-1 or its receptor, CCR2, in atherosclerotic lesion formation. $\mathrm{Gu}$ et al reported less lipid deposition and fewer macrophages in the aortic walls of LDL-receptor deficient mice lacking also the MCP-1 encoding gene (13). Similarly, Boring et al, using ApoE-/- knockout mice, observed an overall decrease in atherosclerotic lesions in mice also deficient of the MCP-1 receptor (14). In addition to those findings, Aiello et al demonstrated that overexpression of MCP-1 in the bone marrow-derived cells of ApoE-/- mice resulted in increased lesion formation as well as increased deposition of oxidized lipid and macrophages (15). Experimental blocking of the MCP-1/CCR2 pathway in atherosclerotic models also resulted in reduction of lesion development. Ni et al and Inoue et al used a mutant analogue of MCP-1 that was able to bind to its receptor, CCR2, without producing activation. When the mutated gene was transfected into the skeletal muscle cells of ApoE-/- mice, atherosclerosis was attenuated (16,17). MCP-1/ CCR2 pathways have also been implicated in the accumulation and migration of SMCs in atherosclerotic lesions. In a study by Roque et al mice deficient in CCR2 significantly reduced intimal hyperplasia following injury to the femoral artery. As macrophage infiltration to the injured femoral arteries of both CCR2+/+ and CCR2-/- mice is negligible, this suggests that MCP-1/CCR2 has an impact on the migration and/or proliferation of SMCs following acute arterial injury (18). Furthermore, a number of population genetic studies have been conducted evaluating susceptibility to atherosclerosis in subjects carrying polymorphic variants of the MCP-1 or CCR2 encoding genes. A G to A substitution in the human CCR2 gene causing a Valine to Isoleucine substitution (CCR2-V64I) has been identified and mostly evaluated (19). Szalai et al evaluated the frequency of the CCR2-V64I polymorphism in 318 CAD patients compared to 320 controls and suggested that patients with the CCR2-V64I polymorphism were at reduced risk for $\mathrm{CAD}$, based on the complete absence of individuals with the rare I/I genotype in the CAD group (20). In a similar cohort of ours conducted in $210 \mathrm{CAD}$ patients and 165 controls, no association between CCR2-V64I and the presence, angiographic severity or clinical presentation of CAD was established (21). Two polymorphisms have been also identified in the $5^{\prime}$ region of the MCP-1 promoter (-2518 
Table I. Chemokines implicated in atherosclerosis.

\begin{tabular}{|c|c|c|c|c|c|c|}
\hline $\begin{array}{l}\text { Chemokine } \\
\text { family }\end{array}$ & $\begin{array}{l}\text { Systemic } \\
\text { name }\end{array}$ & $\begin{array}{l}\text { Alternative } \\
\text { name }\end{array}$ & Receptor & Main cellular sources & Main targets & References \\
\hline \multirow[t]{11}{*}{$\mathrm{CC}$} & CCL1 & I-309 & CCR8 & Endothelial cells & Monocytes/macrophages & 36 \\
\hline & CCL2 & MCP-1 & CCR2 & $\begin{array}{l}\text { Monocytes/macrophages, endothelial } \\
\text { cells, smooth muscle cells }\end{array}$ & $\begin{array}{l}\text { Monocytes/macrophages, } \\
\text { activated T cells }\end{array}$ & $9-17$ \\
\hline & CCL3 & MIP- $1 \alpha$ & CCR1, CCR5 & Monocytes/macrophages, T-cells & $\begin{array}{l}\text { Monocytes/macrophages, } \\
\text { activated T cells }\end{array}$ & $31-33$ \\
\hline & CCL4 & MIP-1ß & CCR5 & Monocytes/macrophages, T-cells & $\begin{array}{l}\text { Monocytes/macrophages, } \\
\text { activated } \mathrm{T} \text { cells }\end{array}$ & $31-33$ \\
\hline & CCL5 & RANTES & $\begin{array}{l}\text { CCR } 1, \text { CCR3, } \\
\text { CCR5 }\end{array}$ & $\begin{array}{l}\text { Monocytes/macrophages, T cells, } \\
\text { platelets }\end{array}$ & $\begin{array}{l}\text { Monocytes/macrophages, } \\
\text { activated } \mathrm{T} \text { cells }\end{array}$ & $23,24,47$ \\
\hline & CCL11 & EOTAXIN & CCR3 & Smooth muscle cells & $\begin{array}{l}\text { Monocytes/macrophages, } \\
\text { mast cells, B cells }\end{array}$ & 27 \\
\hline & CCL13 & MCP-4 & CCR2, CCR3 & $\begin{array}{l}\text { Endothelial cells, monocytes/ } \\
\text { macrophages, T cells }\end{array}$ & $\begin{array}{l}\text { Monocytes/macrophages, } \\
\text { activated T cells }\end{array}$ & 38 \\
\hline & CCL17 & TARC & $\mathrm{CCR} 4$ & $\begin{array}{l}\text { Monocytes/macrophages, } \\
\text { dendritic cells }\end{array}$ & Th2 T cells, dendritic cells & 35 \\
\hline & CCL18 & PARC & Unknown & $\begin{array}{l}\text { Monocytes/macrophages, } \\
\text { dendritic cells }\end{array}$ & Resting T cells & 34 \\
\hline & CCL19 & ELC & CCR7 & $\begin{array}{l}\text { Monocytes/macrophages, } \\
\text { smooth muscle cells }\end{array}$ & Activated T cells & 34 \\
\hline & CCL22 & MDC & CCR4 & $\begin{array}{l}\text { Monocytes/macrophages, } \\
\text { dendritic cells }\end{array}$ & Activated $\mathrm{T}$ cells & 35 \\
\hline \multirow[t]{7}{*}{$\mathrm{CXC}$} & CXCL1 & GRO- $\alpha$ & CXCR2 & $\begin{array}{l}\text { Monocytes/macrophages } \\
\text { endothelial cells }\end{array}$ & Monocytes/macrophages & 44,45 \\
\hline & CXCL4 & PF4 & Unknown & Platelets, monocytes/macrophages & Endothelial cells & $50-54$ \\
\hline & CXCL8 & IL-8 & $\begin{array}{l}\text { CXCR } 1 \\
\text { CXCR2 }\end{array}$ & $\begin{array}{l}\text { Monocytes/macrophages, } \\
\text { endothelial cells, smooth muscle cells }\end{array}$ & $\begin{array}{l}\text { Endothelial cells, monocytes/ } \\
\text { macrophages, smooth muscle cells, } \\
\text { T cells }\end{array}$ & $40-43$ \\
\hline & CXCL9 & MIG & CXCR3 & $\begin{array}{l}\text { Endothelial cells, monocytes/ } \\
\text { macrophages }\end{array}$ & Activated T cells & 46 \\
\hline & CXCL10 & IP-10 & CXCR3 & $\begin{array}{l}\text { Endothelial cells monocytes/ } \\
\text { macrophages, smooth muscle cells }\end{array}$ & Activated T cells & 46 \\
\hline & CXCL11 & I-TAC & CXCR3 & $\begin{array}{l}\text { Monocytes/macrophages, } \\
\text { endothelial cells }\end{array}$ & Activated $\mathrm{T}$ cells & 46 \\
\hline & CXCL12 & SDF1- $\alpha$ & CXCR4 & $\begin{array}{l}\text { Monocytes/macrophages, } \\
\text { smooth muscle cells }\end{array}$ & $\begin{array}{l}\text { T cells, platelets, } \\
\text { smooth muscle cell progenitors }\end{array}$ & 48,49 \\
\hline $\mathrm{CX} 3 \mathrm{C}$ & CX3CL1 & Fractalkine & CX3CR1 & Endothelial cells, smooth muscle cells & $\begin{array}{l}\text { Monocytes/macrophages, activated } \\
\text { T cells, smooth muscle cells }\end{array}$ & $56-59$ \\
\hline
\end{tabular}

MCP, monocyte chemoattractant protein; MIP, macrophage inflammatory protein; RANTES, regulated on activation normal T cell expressed and secreted; TARC, thymus and activation-regulated chemokine; PARC, pulmonary and activation-regulated chemokine; ELC, Epstein-Barr virus-induced molecule 1 ligand chemokine; MDC, macrophage-derived chemokine; GRO, growth related oncogene; PF platelet factor; IL, interleukin; MIG, monokine induced by IFN- $\gamma$; IP-10, 10-kDa IFN- $\gamma$-inducible protein; I-TAC, IFN- $\gamma$-inducible T cell $\alpha$-chemoattractant; SDF, stromal cell-derived factor.

A to $\mathrm{G}$ and -2076 A to $\mathrm{T})$. The -2518 polymorphism has been reported to have functional effects (22). In support of these, Szalai et al investigated the prevalence of the $-2518 \mathrm{G}$ polymorphism in coronary artery diseased (CAD) patients and healthy controls and reported a significantly higher frequency of the $-2518 \mathrm{G}$ homozygote variant of the MCP-1 promoter in
CAD patients than in controls, thus implicating the MCP-1/ CCR2 pathway in atherosclerosis (20).

RANTES and CC receptor 5. RANTES (regulated on activation, normal $\mathrm{T}$ cell expressed and secreted,) or CCL5 is expressed by $\mathrm{T}$ lymphocytes in advanced lesions and is 
highly produced in human transplant-associated accelerated atherosclerosis by macrophages, lymphocytes, myofibroblasts and endothelial cells. Pattison et al investigated the expression of RANTES using in situ hybridization and immunohistochemistry in coronary arteries of patients undergoing accelerated atherosclerosis compared to normal coronary arteries (23). They demonstrated that RANTES mRNA and protein were detected in the lymphocytes, macrophages, myofibroblasts and endothelial cells of arteries undergoing accelerated atherosclerosis but not in normal coronary arteries, concluding that RANTES may be a pivotal mediator of the cellular infiltrate seen in graft atherosclerosis. In a completely different setting, Veillard et al reported that blocking in vivo RANTES-mediated signalling using the CC chemokine antagonist Met-RANTES, reduced the progression of atherosclerosis in a hypercholesterolemic mouse model, indicating that blockade of chemokine receptor/ligand interactions could become a novel therapeutic target decelerating the progression of atherosclerosis (24).

The role of CCR5/RANTES pathway was also investigated by population-based genetic studies. Genetic changes in the CCR5/RANTES system may influence the development of CAD. A 32-base-pair deletion in the CCR5 receptor (CCR5 $\triangle 32$ ) and two promoter polymorphisms in RANTES (-28 C to $\mathrm{G}$ and $-403 \mathrm{G}$ to $\mathrm{A}$ ) have been identified and thoroughly investigated. Studies based on screening the 32-base-pair deletion in the CCR5 receptor gene and its association with CAD, have produced conflicting conclusions. Szalai et al [20] reported that the CCR5 $\Delta 32$ genotype has an atheroprotective effect, since they found a higher frequency of CCR5- $\Delta 32$ homozygotes in controls than in CAD patients. Similarly, Gonzalez et al (25) demonstrated that non-carriers of the CCR5- $\Delta 32$ allele had a three-times greater risk of MI under 55 years of age. Finally, in a study of ours, the frequency of CCR5- $\triangle 32$ was evaluated in 210 angiographically-assessed CAD patients and 165 controls with negative coronary angiography. No differences were observed. However, the frequency of deletion in the population studied was relatively low, limiting the power of a negative association (21). The effect of polymorphisms of RANTES has also been investigated by several cohorts. Szalai et al found no association between RANTES polymorphisms -28G and -403A and CAD (20). In a recent study by Boger et al, contacted in type 2 diabetics in end-stage renal disease, patients carrying the RANTES -403A or In 1.1C allele of the intronic In1.1T/C polymorphism had a significantly higher "all cause" mortality risk, mainly due to cardiac events (26).

Eotaxin and CC receptor 3 . Haley et al, using DNA microarray technology and subsequent Northern analyses, demonstrated a marked increase in eotaxin (CCL11) mRNA in cultured human aortic SMCs treated with tumor necrosis factor- $\alpha$ $(\mathrm{TNF}-\alpha)$. In the same study, immunohistochemical analysis demonstrated overexpression of eotaxin protein and its receptor, CCR3, in human atheromas, with negligible expression in normal vessels, suggesting that eotaxin participates in vascular inflammation (27). The evaluation of circulating levels of eoataxin as a marker of atherosclerosis revealed inconclusive results. In a study by Emanuele et al, increased eotaxin circulating levels were associated with presence and angeographic severity of CAD (28), while Mosedale et al evaluated by ELISA eotaxin and MCP-1 circulating levels in patients with atherosclerosis and normal subjects and conclude that, although there may be a transient increase in circulating chemokine levels following coronary angioplasty, there is no difference in the levels of circulating MCP-1 or eotaxin in subjects with or without atherosclerosis (29).

MIP-1 chemokines. Macrophage inflammatory protein- $1 \alpha$ (MIP-1 $\alpha$ ) was identified 15 years ago. It was the first of the currently known four members of the MIP-1 chemokine subfamily. These proteins are produced by many cells, particularly macrophages, dendritic cells, and lymphocytes. Despite their structural similarities, MIP-1 subtypes show diverging signalling capacities (30). Several studies in the literature imply a role for the MIP chemokines in atherogenesis. Lutgens et $a l$, in a study involving microarray analysis on mRNA of aortic arches of ApoE-/- mice fed normal chow or Western-type diet revealed important functions for genes involved in inflammation, especially the small inducible cytokines, MCP-1, MCP-5, MIP-1 $\alpha$, MIP-1ß, MIP-2, and fractalkine. Further expression and in vivo validation studies showed that this gene cluster mediates plaque progression and stability (31). Additionally, Holven et al demonstrated, among others, significantly higher levels of spontaneouslyreleased MIP- $1 \alpha$ and MIP-1ß by peripheral blood mononuclear cells (PBMCs) in patients with familial hypercholesterolemia (FH). The authors concluded that one of the pathophysiological consequences of FH is enhanced chemokine responses which, in turn, may promote recruitment and activation of leukocytes within the vessel wall, contributing to atherosclerosis (32). Additionally, drugs with anti-inflammatory anti-atherogenic properties, such as hydroxymethylglutaryl (HMG)-CoA reductase inhibitors, have been shown to down-regulate $\mathrm{CC}$ chemokine ligands and receptors. Veillard et al used human vascular endothelial cells and human primary macrophages, stimulated with tumor necrosis factor (TNF)- $\alpha$ or interferon (IFN)- $\gamma$, respectively. They demonstrated by ELISA that $1 \mathrm{mM}$ simvastatin significantly reduced MCP-1 in endothelial cells and macrophages. Further mRNA analysis revealed that expression of the chemokines, MCP-1, MIP- $1 \alpha$ and MIP-1ß, as well as the chemokine receptors, CCR1, CCR2, CCR4 and CCR5, was decreased by simvastatin, both in endothelial cells and macrophages (33).

Novel CC chemokines. Novel members of CC chemokines and potent chemoattractants for lymphocytes, such as pulmonary and activation-regulated chemokine (PARC) or CCL18, Epstein Barr virus-induced molecule 1 ligand chemokine (ELC) or CCL19, liver and activation-regulated chemokine (LARC) or CCL20 and secondary lymphoid-tissue chemokine (SLC) or CCL21 have been also evaluated in atherosclerosis. Reape et al, using reverse transcriptase-polymerase chain reaction and in situ hybridization methodologies, demonstrated gene expression for PARC and ELC but not for LARC or SLC in human atherosclerotic plaques. Immunohistochemical staining of serial plaque sections with specific cell markers revealed highly different expression patterns of PARC and ELC. They further demonstrated, in vitro, up-regulation of 
ELC mRNA in aortic SMC stimulated with TNF- $\alpha$ and IFN- $\gamma$ but not in SMCs stimulated with serum. Both PARC and ELC mRNA were expressed by monocyte-derived macrophages but not by monocytes (34).

Greaves et al analyzed the expression of the linked chromosome 16q13 genes that encode macrophage-derived chemokine (MDC/CCL22), thymus- and activation-regulated chemokine (TARC/CCL17), and the CX3C chemokine, fractalkine (CX3CL1), in primary macrophages and human atherosclerotic lesions by reverse transcription-polymerase chain reaction and immunohistochemistry. Expression of all the studied chemokines was up-regulated in interleukin-4- and interleukin-13 treated macrophages. Immunohistochemistry showed that MDC, fractalkine, and TARC were expressed by a subset of macrophages within regions of plaques that contain plaque microvessels. Greaves et al concluded that MDC, fractalkine, and TARC could play a role in mononuclear cell recruitment into atherosclerotic lesions and influence the subsequent inflammatory response (35).

Haque et al demonstrated that I-309 (CCL1), a novel CC chemokine produced by $\mathrm{T}$ lymphocytes and stimulated monocytes, was produced by endothelial cells and was responsible for the monocyte chemotactic activity induced by $\mathrm{Lp}(\mathrm{a})$ in human umbilical vein endothelial cells. The identification of endothelial cells as a source for I-309 suggests that this chemokine may participate in vessel wall biology and particularly in Lp(a)-mediated effects in atherosclerosis (36). Haque et al further demonstrated that I-309 stimulates chemotaxis of human vascular smooth muscle cells (VSMCs) and that this chemotaxis is blocked by murine monoclonal antibody against the I-309 receptor (CCR8) and by the G-protein inhibitor, pertussis toxin, concluding that induction of CCR8 and CCL1 under conditions associated with VSMC proliferation and migration raises the possibility that CCR8 may play an important role in vessel wall pathology (37).

Finally, Berkhout et al described and characterized the novel human $\mathrm{CC}$ chemokine, monocyte chemotactic protein (MCP)-4. MCP-4 induced a potent chemotactic response in peripheral blood monocytes but not in neutrophils. Binding studies in monocytes showed that MCP-4 interacts with the $\mathrm{CC}$ chemokine receptor-2 (MCP-1 receptor). Furthermore, expression of MCP-4 protein was demonstrated by immunohistochemistry in human atherosclerotic lesions and found to be associated with endothelial cells and macrophages. The authors concluded that MCP-4, like MCP-1, may be involved in the recruitment of monocytes into the arterial wall during atherosclerosis (38).

\section{The CXC chemokines and chemokine receptors}

The CXC chemokines are the second largest class. As mentioned before, CXC chemokines have a single amino acid residue separating their two amino-terminal cysteins. They can be further structurally subdivided into two groups based on the presence or absence of an ELR (Glu-Leu-Arg) amino acid motif in their amino-terminal domain. Examples of ELR ${ }^{+}$and ELR- CXC chemokines are interleukin (IL)-8 and $10 \mathrm{kDa}$ IFN- $\gamma$ inducible protein (IP)-10, respectively (39). Since CXC chemokines are mainly neutrophil chemoattractants, they have received less attention concerning their role in the pathogenesis of atherosclerosis. However, regarding IL-8 (or CXCL8), IP-10 (or CXCL10) and stromal cell derived factor (SDF)-1 or CXCL12, in particular, there is convincing evidence in the literature supporting their role in atherogenesis.

IL-8 and CXC receptors 2 . Since the discovery of IL-8, the prototype of CXC chemokines, in 1987, the knowledge on its role in leukocyte infiltration has advanced rapidly with increasing interest in the implications of IL- 8 in vascular pathology. Apostolopoulos et al demonstrated the expression of IL-8 in human atherosclerotic plaques by in situ hybridisation (40). IL-8 has been shown to contribute in SMC proliferation and migration (41) and, despite the fact that IL-8 has been thought to act predominantly on neutrophils, Gerszten et al demonstrated that it induced firm adhesion of rolling monocytes to endothelial monolayers expressing Eselectin (42). Additional supporting evidence for a potential role for $\mathrm{CXC}$ chemokines in atherogenesis came from an experiment by Boisvert et al, in which LDL receptor knockout mice which were irradiated and repopulated with bone marrow cells lacking the murine homologue of IL- 8 receptor CXCR2 had less extensive lesions and fewer macrophages than those mice receiving bone marrow cells expressing the receptor (43). Schwartz et al reported that another ligand of CXCR2, growthrelated oncogene (GRO)- $\alpha$ or CXCL1 may contribute to adhesion of monocytes to minimally modified-LDL stimulated endothelial cells similarly to IL-8 (44) and, in a more recent study by Hue et al, using isolated carotid artery from ApoE-/mice demonstrated that GRO- $\alpha$ but not MCP-1 plays a role in monocyte arrest on the endothelium of atherosclerosis-prone vessels (45). The above studies clearly suggest an important role of CXCR2-mediated pathways in the accumulation and migration of monocytes into the intima, and suggest that multiple ligands of CXCR2 may be key participants in the pathogenesis of atherosclerosis.

IP-10, I-TAC, MIG and CXC receptor 3. The chemokine receptor, CXCR3, has multiple high-affinity CXC chemokine ligands including IP-10, monokine-induced by IFN- $\gamma$ (MIG) or CXCL9 and IFN- $\gamma$ inducible T-cell $\alpha$-chemoattractant (I-TAC) or CXCL11. Mach et al demonstrated different levels of expression of IP-10, MIG, and I-TAC by atheromaassociated cells and suggested a potential role for these 3 IFN- $\gamma$-inducible CXC chemokines in the recruitment and retention of activated $\mathrm{T}$ lymphocytes observed within the vascular wall during atherogenesis (46).

SDF-1 and PF4. Platelets represent both a source and a target for chemokines that may be involved in the process of atherogenic recruitment. Platelets secrete both CXC chemokines, such as platelet factor (PF) 4 or CXCL4 and epithelial neutrophil-activating protein (ENA)-78 or CXCL5, and CC chemokines, such as MIP-1 $\alpha$ and RANTES (47). Abi-Younes et al reported that, of the 16 chemokines tested, only SDF-1 induced platelet aggregation and proposed an involvement of SDF-1 in the pathogenesis of atherosclerosis and thromboocclusive diseases (48). Additionally, Schober et al investigated the involvement of SDF-1 in neointimal formation after vascular injury. SDF-1 was detected in the carotid arteries of ApoE-/- mice after wire-induced injury and was mostly located 
at SMCs. Furthermore, treatment of ApoE-/- mice after carotid injury with a neutralizing SDF-1 monoclonal antibody reduced neointimal lesion area, and decreased neointimal SMC content without influencing the relative content of neointimal macrophages. Thus, the authors concluded that SDF-1 plays an active role in neointimal formation after vascular injury in ApoE-/- mice by regulating neointimal SMC content (49). The role of SDF-1 in atherogenesis has also been investigated by population genetic surveys. Nevertheless, both studies that evaluated the effect of the common single nucleotide polymorphism, G801A, of the SDF-1A gene on susceptibility to CAD have concluded no association $(20,21)$.

As mentioned previously, activated platelets secrete a number of chemokines of both CC and CXC subgroups. The role of platelet-derived chemokines in atherosclerosis has been the subject of several studies in recent literature. PF4, a CXC-chemokine member secreted by platelets, induces upregulation of monocyte activation, firm adherence of neutrophils on shear stressed endothelium, and release of neutrophil granule components $(50,51)$. Pitsilos et al detected PF4 in the cytoplasm of luminal and neovascular endothelium, in macrophages and in regions of plaque calcification. The presence of PF4 in macrophages and neovascular endothelium significantly correlated with lesion grade (52). Furthermore, in a recent study, $\mathrm{Yu}$ et al demonstrated that E-selectin, an adhesion molecule involved in atherogenesis, is up-regulated in human umbilical vein endothelial cells exposed to PF4 (53). Finally, Nassar et al showed that PF4 bound to oxidized (ox)LDL directly, and also increased ox-LDL binding to vascular cells and macrophages, thus demonstrating an alternative mechanism by which platelet activation at sites of vascular injury may promote the accumulation of deleterious lipoproteins (54).

\section{The CX3C chemokine and chemokine receptor}

CX3C chemokines include an amino-terminal domain with a novel arrangement of three amino acids separating their first two cysteines. Fractalkine or CXCL1 is the only currently known member of the $\mathrm{CX} 3 \mathrm{C}$ chemokine subfamily. It exists as membrane-bound and in soluble form. Membrane-bound fractalkine consists of an extracellular domain of 76 amino acids connected to an extended mucin-like stalk, followed by transmembrane and intracellular domains of 34 amino acids. Soluble fractalkine is released, presumably by proteolysis, at the membrane-proximal region by TNF- $\alpha$-converting enzyme. Soluble fractalkine has been proved to be an efficient chemoattractant for monocytes and natural killer cells. The receptor of fractalkine (CX3CR1) is a seven-transmembrane domain $\mathrm{G}$ protein-coupled receptor, and fractalkine binds to it with high affinity, activating intracellular signalling and directly mediating monocyte adhesion $(55,56)$.

Through its unique structural and functional characteristics, fractalkine displays properties of both chemokine and adhesion molecules $(55,56)$. It also possesses chemoattractant activities for both monocytes and T cells and is up-regulated in cytokinestimulated endothelial cells (56). Fractalkine is, therefore, a "perfect" candidate for an exceptional role in the pathogenesis of atherosclerosis. Indeed, fractalkine and its receptor, CX3CR1, have been implicated in atherogenesis by several studies under different settings. Immunochemical studies have confirmed its expression in monocytes/macrophages, endothelial and SMCs within human atherosclerotic coronary arteries (57). Additionally, Lucas et al reported that SMCs in the neointima of human atherosclerotic plaques express CX3CR1. They further demonstrated that primary cultured human coronary artery SMCs migrate toward fractalkine, suggesting that CX3CR1 also induces migration of SMCs to atherosclerotic lesions (58). Combadiere et al, by testing the potential role of fractalkine in double knockout mice (ApoE-/-, CX3CR1-/-), showed a significant decrease in lesion size in animals lacking the fractalkine-CX3CR1 signalling mechanism (59). Recent studies have also implicated fractalkine in platelet stimulation and activation. Activated platelets have been shown to exacerbate atherosclerosis in murine models of atherogenesis. Schafer et al demonstrated that platelets from rats, pre-incubated with fractalkine, had increased P-selectin surface expression. Also, pre-incubation with fractalkine enhanced platelet adhesion to collagen and fibrinogen (60).

In support of this evidence, several population-based genetic studies conducted in different population samples evaluated the effect of genetic variations of the $\mathrm{CX} 3 \mathrm{C}$ receptor on susceptibility to coronary artery disease. Two polymorphisms were identified in the CX3CR1 gene, one which causes a codon change from valine to isoleucine at position 249 (CX3CR1V249I), and another that causes a codon change from threonine to methionine at position 280 (CX3CR1-T280M). These changes are located in the sixth and seventh transmembrane domains, respectively (61). Several studies conducted in different population samples revealed an atheroprotective effect of these common single nucleotide polymorphisms of the $\mathrm{CX} 3 \mathrm{C}$ receptor gene which have been shown to reduce the activity of the fractalkine-CX3CR1 pathway $(21,62-64)$. Furthermore, subjects carrying these polymorphisms not only had mononuclear cells with decreased numbers of fractalkine binding sites (62) but also showed improved endotheliumdependent vasodilation (63).

The structural and functional uniqueness of fractalkine, demonstrated by multiple studies under different settings have clearly established a key role for fractalkine and its receptor in atherogenesis.

\section{The $\mathrm{C}$ chemokines and chemokine receptors}

The $\mathrm{C}$ chemokine family is represented by two chemokines, XCL1/lymphotactin- $\alpha$ and XCL2/lymphotactin- $\beta$. Human lymphotactins recruit $\mathrm{T}$ lymphocytes and natural killer cells by interacting with their specific receptor, XCR1, in normal immune function and chronic inflammatory conditions (65). Nevertheless, there is currently no evidence in the literature supporting a critical role for $\mathrm{C}$ chemokines in atherosclerosis.

\section{Discussion}

Recent literature provides convincing evidence that chemokines are involved in all aspects of atherosclerosis; orchestration, migration, proliferation and accumulation of the cell populations participating in atherosclerosis. It is well established that atherosclerosis is a chronic inflammatory process taking place in the vascular wall. Chemokines are important mediators 

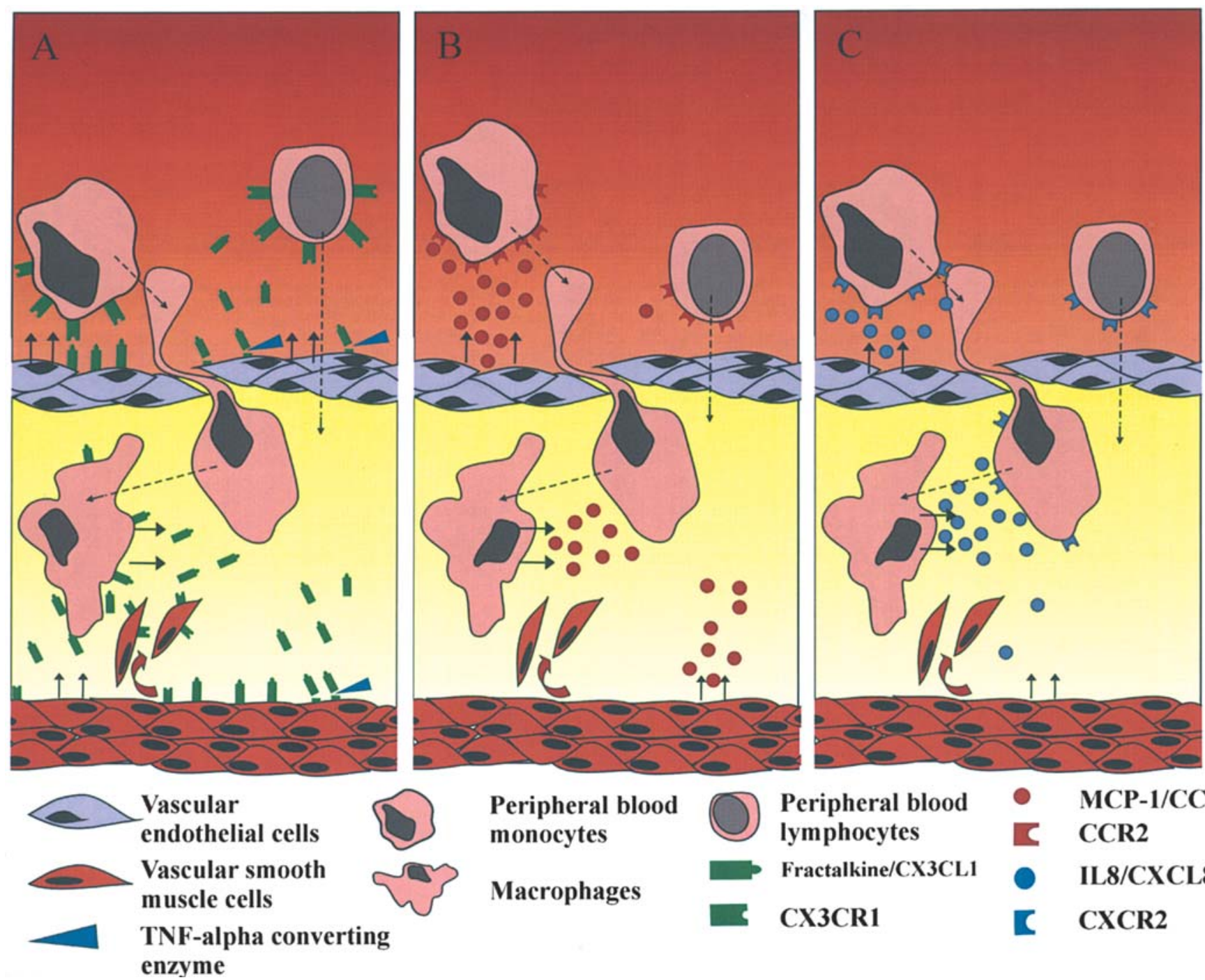

\section{Peripheral blood monocytes}

Macrophages enzyme

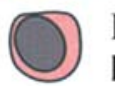

Fractalkine/CX3CL1

CX3CR1
- MCP-1/CCL2 C CCR2

IL8/CXCL8

C $\mathrm{CXCR2}$

Figure 1. Schematic presentation of the main chemokine-mediated pathways involved in atherosclerosis. Fractalkine is expressed by vascular endothelial cells, smooth muscle cells and presumably by macrophages of the intima and acts either as a chemotactic cytokine or as an adhesion molecule. In both forms fractalkine promotes the accumulation and migration of monocytes and $\mathrm{T}$ cells in atherosclerotic lesions. It has been also implicated in vascular smooth muscle cell migration in the process of advanced-lesion formation (A). MCP-1 is highly expressed by lesions' macrophages but also by endothelial cells and smooth muscle cells and is a major chemoattractant for circulating monocytes and activated T cells. MCP-1/CCR2 pathways have also been implicated in the accumulation and migration of smooth muscle cells in atherosclerotic lesions. (B). Finally IL-8 is expressed by vascular endothelial cells, smooth muscle cells and macrophages and is a potent chemoattractant for circulating monocytes and $\mathrm{T}$ cells. It has been also shown to contribute in smooth muscle cell proliferation and migration $(\mathrm{C})$.

of inflammation and have been implicated in a specific or non-specific manner in almost every inflammatory disease. Several chemokine ligands and receptors have been extensively investigated and have been proved to be involved in more disease-specific ways in atherosclerosis. We consider MCP1/ CCR2, IL-8/CXCR2 and fractalkine/CX3CR1 as the key chemokine-receptor pathways most definitely participating in atherogenesis (Fig. 1). Their role has been demonstrated by studies conducted in in vitro systems, in animal models of accelerated atherosclerosis, and in genetic epidemiology studies. Nevertheless, an important issue is whether knowledge derived from indirect investigations can be applied in disease management practices. Further clinical evaluations are clearly required to establish the diagnostic or prognostic potential of these chemokines in atherosclerosis and, perhaps, to rationally design strategies for chemokines and their receptors as therapeutic targets.
Chemokines as markers of atherosclerosis. The inflammatory process participates in the pathogenesis of atherosclerosis and affects clinical presentation of atherosclerotic disease. Several mediators of inflammation have been tested as potential markers of atherosclerosis. Elevation of plasma C-reactive protein, using new sensitive assays, predicts an increased risk of cardiovascular events in patients with unstable and stable angina pectoris. An association between elevated plasma levels of intercellular adhesion molecule (I-CAM) and risk of coronary heart disease has also been established (66). Circulating levels of chemokine ligands and receptors have also been investigated as potential markers of atherosclerosis with controversial results. The most promising evidence comes from studies evaluating serum levels of MCP-1. In a large population-based study by Deo et al, plasma levels of MCP-1 were associated with traditional risk factors for atherosclerosis. The results support the hypothesis that MCP-1 may mediate 
some of the atherogenic effects of these risk factors and underlie the potential role of MCP-1 as a biomarker and target for drug development (67). In a more recent study by Hoogeveen et al, mean plasma MCP-1 levels were found to be significantly higher in peripheral artery disease patients than controls. MCP-1 levels correlated significantly with other inflammatory markers in comparison subjects. Furthermore, incident coronary heart disease was significantly associated with increased MCP-1 levels, independent of other cardiovascular risk factors, suggesting that MCP-1 is associated with atherosclerotic disease in two different vascular pathologies (68). Finally and most impressively, in a large cohort, De Lemos et al demonstrated that, in patients with acute coronary syndromes, an elevated baseline level of MCP-1 was associated with both traditional risk factors for atherosclerosis as well as an increased risk of death or myocardial infarction, independent of baseline variables. Thus, MCP-1 appears to play a crucial role at multiple stages of atherosclerosis, and is a potent alternative biomarker and a possible therapeutic target (69). Similarly to the above, Romuk et al evaluated levels of CXC chemokine IL- 8 and demonstrated significantly higher levels of IL-8 in unstable coronary heart disease patients in comparison to stable coronary heart disease patients and controls, concluding that a soluble form of IL-8 may be a useful clinical predictor of unstable coronary heart disease (70).

Nevertheless, there are still several limitations in the use of circulating chemokines as markers of atherosclerosis, mainly due to the low specificity of such tests. However, reports on circulating levels of chemokines as markers of atherosclerotic activity under experimental conditions are encouraging. For instance, Troseid et al evaluated the effect of physical exercise on vascular inflammation using peripheral markers of inflammation in subjects with metabolic syndrome and demonstrated a significant reduction in MCP-1 and IL-8 in the combined exercise groups compared to the combined non-exercise groups, proposing that the protective effect of exercise might, in part, be due to suppression of the inflammatory process (71).

Additionally, prognostic genotyping evidence from recent literature seems promising. According to several studies, the presence of certain chemokine polymorphisms independent of other established risk factors has been associated with increased prevalence of CAD, acute coronary syndromes, and other cerebrovascular pathologies $(21,62-64,72)$. Thus, such polymorphisms could potentially be applied to identify patients with a high risk of developing atherosclerosis and render a more precise estimation of the individual's overall cardiovascular risk.

Chemokine ligands and receptors as therapeutic targets. Chemokines are important therapeutic targets. Most of the efforts in this area have been directed towards the development of chemokine receptor antagonists. Currently, there are several studies available in the literature evaluating chemokine receptor antagonists as therapeutic targets in several diseases. For instance, regarding CC chemokines, the efficacy of CCR1 antagonists is being evaluated for the treatment of rheumatoid arthritis and multiple sclerosis. A monoclonal antibody blocking the binding of MCP-1 to CCR2 is also being tested for the treatment of rheumatoid arthritis. CCR5 antagonists that block HIV entry into cells (AOP-RANTES, met-RANTES) are being evaluated in advanced clinical trials as adjuvant treatments for AIDS. Furthermore, small-molecule inhibitors of CX3CR1 are being tested as a potential treatment for psoriasis and rheumatoid arthritis, and CXCR4 antagonists are being evaluated for efficacy in rheumatoid arthritis and cancer $(73,74)$. Chemokine receptors have thus proven to be attractive therapeutic targets, especially regarding traditional inflammation-mediated diseases.

Chemokine antagonists have been proposed for potential treatment of vascular disease. Ni et al demonstrated a new strategy for anti-MCP-1 gene therapy to treat atherosclerosis by transfecting an $\mathrm{N}$-terminal deletion mutant of the human MCP-1 gene into the skeletal muscle in ApoE-/- mice. This strategy effectively blocked MCP-1 activity and inhibited the formation of atherosclerotic lesions. Furthermore, it increased the lesional extracellular matrix content. Authors demonstrated that anti-MCP-1 gene therapy may serve not only to reduce atherogenesis but also to stabilize vulnerable atheromatous plaques and proposed that this strategy could be a useful and plausible form of gene therapy against atherosclerosis in humans (16). Additionally, Inoue et al reported that blockade of MCP-1 by transfecting an N-terminal deletion mutant of the MCP-1 gene limited progression of pre-existing atherosclerotic lesions in the aortic root in hypercholesterolemic mice and changed the lesion composition into a more stable phenotype. This strategy decreased expression of CD40 and the CD40 ligand in the atherosclerotic plaque and normalized the increased chemokine and cytokine gene expression, suggesting that MCP-1 is an essential mediator in the progression and destabilization of established atheroma (17).

Restenosis may be a more promising target for chemokine antagonists than atherosclerosis. Prevention of restenosis after coronary intervention is a major clinical problem, which highlights the need for new therapeutic options. Usui et al demonstrated that transfection of an $\mathrm{N}$-terminal deletion mutant of the MCP-1 gene into skeletal muscles suppressed monocyte infiltration/activation in the injured site and markedly inhibited restenotic changes after balloon injury of the carotid artery in rats and monkeys. This strategy also suppressed the local production of MCP-1 and inflammatory cytokines. The authors concluded that monocyte infiltration and activation mediated by MCP-1 are essential in the development of restenotic changes after balloon injury and suggested this strategy as a potential form of gene therapy against human restenosis (75).

Although studies in mice and rats have established the importance of chemokines, particularly that of MCP-1, in the development of atherosclerosis, large-scale studies evaluating end points such as acute coronary syndrome or cardiovascular cause of death, are essential to substantiate the use of chemokine antagonists in the treatment of cardiovascular disease in humans.

It might be some time before chemokine antagonists are available for the treatment or prevention of atherosclerosis. However, there is evidence that several agents already in use as a treatment of either atherosclerosis or its risk factors modify chemokine expression. For instance, HMG-CoA reductase inhibitors have been demonstrated by several studies to reduce, 
in vitro and in vivo, the expression of several markers of vascular inflammation, including chemokines (33). Similar findings have been demonstrated for angiotensin converting enzyme (ACE) inhibitors, angiotensin II receptor blockade and glitazones (76-78). Thus, some widely used anti-atherogenic drugs could mediate their beneficial actions partially through inhibition of certain chemokine pathways.

In conclusion, in the past few years we have witnessed a rapid increase in our understanding of the role of chemokines and their receptors in cardiovascular pathologies. Nevertheless, all investigators agree on the fact that the precise mechanism of the chemokine pathways involved in the establishment and progression of atherosclerosis is not fully elucidated and much more information is needed before chemokine-based therapies can be applied in clinical practice.

\section{References}

1. Ross R: Atherosclerosis - an inflammatory disease. N Engl J Med 340: 115-126, 1999.

2. Libby P: Inflammation in atherosclerosis. Nature 420: 868-874, 2002.

3. Luster AD: Chemokines - chemotactic cytokines that mediate inflammation. N Engl J Med 338: 436-445, 1998.

4. Curnock AP, Logan MK and Ward SG: Chemokine signalling: pivoting around multiple phosphoinositide 3-kinases. Immunology 105: 125-136, 2002.

5. Puneet $\mathrm{P}$, Moochhala $\mathrm{S}$ and Bhatia $\mathrm{M}$ : Chemokines in acute respiratory distress syndrome. Am J Physiol Lung Cell Mol Physiol 288: L3-L15, 2005.

6. Amanatidou V, Sourvinos G, Apostolakis S, Tsilimigaki A and Spandidos DA: T280M variation of the CX3C receptor gene is associated with increased risk for severe respiratory syncytial virus bronchiolitis. Ped Inf Dis J (in press).

7. Tripp RA: Pathogenesis of respiratory syncytial virus. Viral Immunology 17: 165-181, 2004.

8. Reape TJ and Groot PH: Chemokines and atherosclerosis. Atherosclerosis 147: 213-225, 1999.

9. Yla-Herttuala S, Lipton BA, Rosenfeld ME, Sarkioja T, Yoshimura T, Leonard EJ, Witztum JL and Steinberg D: Expression of monocyte chemoattractant protein 1 in macrophage-rich areas of human and rabbit atherosclerotic lesions. Proc Natl Acad Sci USA 88: 5252-5256, 1991.

10. Takeya M, Yoshimura T, Leonard EJ and Takahashi K: Detection of monocyte chemoattractant protein-1 in human atherosclerotic lesions by an anti-monocyte chemoattractant protein-1 monoclonal antibody. Hum Pathol 24: 534-539, 1993.

11. Nelken NA, Coughlin SR, Gordon D and Wilcox JN: Monocyte chemoattractant protein-1 in human atheromatous plaques. J Clin Invest 88: 1121-1127, 1991.

12. Seino Y, Ikeda U, Takahashi M, Hojo Y, Irokawa M, Kasahara T and Shimada K: Expression of monocyte chemoattractant protein-1 in vascular tissue. Cytokine 7: 575-579, 1995.

13. Gu L, Okada Y, Clinton SK, Gerard C, Sukhova GK, Libby P and Rollins BJ: Absence of monocyte chemoattractant protein-1 reduces atherosclerosis in low density lipoprotein receptordeficient mice. Mol Cell 2: 275-281, 1998.

14. Boring L, Gosling J, Cleary M and Charo IF: Decreased lesion formation in CCR2-/- mice reveals a role for chemokines in the initiation of atherosclerosis. Nature 394: 894-897, 1998.

15. Aiello RJ, Bourassa PA, Lindsey S, Weng W, Natoli E, Rollins BJ and Milos PM: Monocyte chemoattractant protein-1 accelerates atherosclerosis in apolipoprotein E-deficient mice. Arterioscler Thromb Vasc Biol 19: 1518-1525, 1999.

16. Ni W, Egashira K, Kitamoto S, Kataoka C, Koyanagi M, Inoue S, Imaizumi K, Akiyama C, Nishida KI and Takeshita A: New anti-monocyte chemoattractant protein-1 gene therapy attenuates atherosclerosis in apolipoprotein E-knockout mice. Circulation 103: 2096-2101, 2001.

17. Inoue S, Egashira K, Ni W, Kitamoto S, Usui M, Otani K, Ishibashi M, Hiasa K, Nishida K and Takeshita A: Anti-monocyte chemoattractant protein-1 gene therapy limits progression and destabilization of established atherosclerosis in apolipoprotein E-knockout mice. Circulation 106: 2700-2706, 2002.
18. Roque M, Kim WJ, Gazdoin M, Malik A, Reis ED, Fallon JT, Badimon JJ, Charo IF and Taubman MB: CCR2 deficiency decreases intimal hyperplasia after arterial injury. Arterioscler Thromb Vasc Biol 22: 554-559, 2002.

19. Lee B, Doranz BJ, Rana S, Yi Y, Mellado M, Frade JM, Martinez AC, O'Brien SJ, Dean M, Collman RG and Doms RW: Influence of the CCR2-V64I polymorphism on human immunodeficiency virus type 1 coreceptor activity and on chemokine receptor function of CCR2b, CCR3, CCR5, and CXCR4. J Virol 72: 7450-7458, 1998.

20. Szalai C, Duba J, Prohaszka Z, Kalina A, Szabo T, Nagy B, Horvath $\mathrm{L}$ and Csaszar A: Involvement of polymorphisms in the chemokine system in the susceptibility for coronary artery disease (CAD). Coincidence of elevated Lp(a) and MCP-1 $2518 \mathrm{G} / \mathrm{G}$ genotype in CAD patients. Atherosclerosis 158: 233-239, 2001.

21. Apostolakis S, Baritaki S, Kochiadakis GE, Igoumenidis NE, Panutsopulos D and Spandidos DA: Effects of polymorphisms in chemokine ligands and receptors on susceptibility to coronary artery disease. Thromb Res (Epub ahead of print), 2006.

22. Rovin BH, Lu L and Saxena R: A novel polymorphism in the MCP-1 gene regulatory region that influences MCP-1 expression. Biochem Biophys Res Commun 259: 344-348, 1999.

23. Pattison JM, Nelson PJ, Huie P, Sibley RK and Krensky AM: RANTES chemokine expression in transplant-associated accelerated atherosclerosis. J Heart Lung Transplant 15: 1194-1199, 1996.

24. Veillard NR, Kwak B, Pelli G, Mulhaupt F, James RW, Proudfoot AE and Mach F: Antagonism of RANTES receptors reduces atherosclerotic plaque formation in mice. Circ Res 94: 253-261, 2004.

25. Gonzalez P, Alvarez R, Batalla A, Reguero JR, Alvarez V, Astudillo A, Cubero GI, Cortina A and Coto E: Genetic variation at the chemokine receptors CCR5/CCR2 in myocardial infarction. Genes Immun 2: 191-195, 2001.

26. Boger CA, Fischereder M, Deinzer M, Aslanidis C, Schmitz G, Stubanus M, Banas B, Kruger B, Riegger GA and Kramer BK: RANTES gene polymorphisms predict all-cause and cardiac mortality in type 2 diabetes mellitus hemodialysis patients. Atherosclerosis 183: 121-129, 2005.

27. Haley KJ, Lilly CM, Yang JH, Feng Y, Kennedy SP, Turi TG, Thompson JF, Sukhova GH, Libby P and Lee RT: Overexpression of eotaxin and the CCR3 receptor in human atherosclerosis: using genomic technology to identify a potential novel pathway of vascular inflammation.Circulation 102: 2185-2189, 2000.

28. Emanuele E, Falcone C, D'Angelo A, Minoretti P, Buzzi MP, Bertona $\mathrm{M}$ and Geroldi D: Association of plasma eotaxin levels with the presence and extent of angiographic coronary artery disease. Atherosclerosis (Epub ahead of print), 2005.

29. Mosedale DE, Smith DJ, Aitken S, Schofield PM, Clarke SC, McNab D, Goddard H, Gale CR, Martyn CN, Bethell HW, Barnard C, Hayns S, Nugent C, Panicker A and Grainger DJ: Circulating levels of MCP-1 and eotaxin are not associated with presence of atherosclerosis or previous myocardial infarction. Atherosclerosis 183: 268-274, 2005.

30. Maurer M and von Stebut E: Macrophage inflammatory protein-1. Int J Biochem Cell Biol 36: 1882-1886, 2004

31. Lutgens E, Faber B, Schapira K, Evelo CT, van Haaften R, Heeneman S, Cleutjens KB, Bijnens AP, Beckers L, Porter JG, Mackay CR, Rennert P, Bailly V, Jarpe M, Dolinski B, Koteliansky V, de Fougerolles $\mathrm{T}$ and Daemen MJ: Gene profiling in atherosclerosis reveals a key role for small inducible cytokines: validation using a novel monocyte chemoattractant protein monoclonal antibody. Circulation 111: 3443-3452, 2005 .

32. Holven KB, Myhre AM, Aukrust P, Hagve TA, Ose L and Nenseter MS: Patients with familial hypercholesterolaemia show enhanced spontaneous chemokine release from peripheral blood mononuclear cells ex vivo. Dependency of xanthomas/ xanthelasms, smoking and gender. Eur Heart J 24: 1756-1762, 2003.

33. Veillard NR, Braunersreuther V, Arnaud C, Burger F, Pelli G, Steffens S and Mach F: Simvastatin modulates chemokine and chemokine receptor expression by geranylgeranyl isoprenoid pathway in human endothelial cells and macrophages. Atherosclerosis (Epub ahead of print), 2005.

34. Reape TJ, Rayner K, Manning CD, Gee AN ,Barnette MS, Burnand $\mathrm{KG}$ and Groot PHE: Expression and cellular localization of the CC chemokines PARC and ELC in human atherosclerotic plaques. Am J Pathol 154: 365-374, 1999. 
35. Greaves DR, Hakkinen T, Lucas AD, Liddiard K, Jones E, Quinn CM, Senaratne J, Green FR, Tyson K, Boyle J, Shanahan C, Weissberg PL, Gordon S, Yla"-Hertualla S: Linked chromosome 16q13 chemokines, macrophage-derived chemokine, fractalkine, and thymus- and activation-regulated chemokine, are expressed in human atherosclerotic lesions. Arterioscler Thromb Vasc Biol 21: 923-929, 2001

36. Haque NS, Zhang X, French DL, Li J, Poon M, Fallon JT, Gabel BR, Taubman MB, Koschinsky M and Harpel PC: CC chemokine I-309 is the principal monocyte chemoattractant induced by apolipoprotein(a) in human vascular endothelial cells. Circulation 102: 786-792, 2000

37. Haque NS, Fallon JT, Pan JJ, Taubman MB and Harpel PC: Chemokine receptor-8 (CCR8) mediates human vascular smooth muscle cell chemotaxis and metalloproteinase-2 secretion. Blood 103: 1296-1304, 2004.

38. Berkhout TA, Sarau HM, Moores K, White JR, Elshourbagy N, Appelbaum E, Reape TJ, Brawner M, Makwana J, Foley JJ, Schmidt DB, Imburgia C, McNulty D, Matthews J, O'Donnell K, O'Shannessy D, Scott M, Groot PHE and Macphee C: Cloning, in vitro expression and functional characterization of a novel human CC chemokine of the MCP family (MCP-4), which binds and signals through the CC chemokine receptor $2 \mathrm{~B}$. J Biol Chem 272: 16404-16413, 1997.

39. Burke-Gaffney A, Brooks AV and Bogle RG: Regulation of chemokine expression in atherosclerosis. Vasc Pharmacol 38: 283-292, 2002 .

40. Apostolopoulos J, Davenport P and Tipping PG: Interleukin-8 production by macrophages from atheromatous plaques. Arterioscler Thromb Vasc Biol 16: 1007-1012, 1996.

41. Yue TL, Wang X, Sung CP, Olson B, McKenna PJ, Gu JL and Feuerstein GZ: Interleukin-8. A mitogen and chemoattractant for vascular smooth muscle cells. Circ Res 75: 1-7, 1994.

42. Gerszten RE, Garcia-Zepeda EA, Lim YC, Yoshida M, Ding HA, Gimbrone MA Jr, Luster AD, Luscinskas FW and Rosenzweig A: MCP-1 and IL-8 trigger firm adhesion of monocytes to vascular endothelium under flow conditions. Nature 398: 718-723, 1999.

43. Boisvert WA, Santiago R, Curtiss LK and Terkeltaub RA: A leukocyte homologue of the IL-8 receptor CXCR-2 mediates the accumulation of macrophages in atherosclerotic lesions of LDL receptor-deficient mice. J Clin Invest 101: 353-363, 1998.

44. Schwartz D, Andalibi A, Chaverri-Almada L, Berliner JA, Kirchgessner T, Fang ZT, Tekamp-Olson P, Lusis AJ, Gallegos C, Fogelman AM, et al: Role of the GRO family of chemokines in monocyte adhesion to MM-LDL-stimulated endothelium. J Clin Invest 94: 1968-1973, 1994.

45. Huo Y, Weber C, Forlow SB, Sperandio M, Thatte J, Mack M, Jung S, Littman DR and Ley K: The chemokine KC, but not monocyte chemoattractant protein-1, triggers monocyte arrest on early atherosclerotic endothelium. J Clin Invest 108: 1307-1314, 2001.

46. Mach F, Sauty A, Iarossi AS, Sukhova GK, Neote K, Libby P and Luster AD: Differential expression of three T lymphocyteactivating CXC chemokines by human atheroma-associated cells. J Clin Invest 104: 1041-1050, 1999.

47. Gear AR and Camerini D: Platelet chemokines and chemokine receptors: linking hemostasis, inflammation, and host defense. Microcirculation 10: 335-346, 2003.

48. Abi-Younes S, Sauty A, Mach F, Sukhova GK, Libby P and Luster AD: The stromal cell-derived factor- 1 chemokine is a potent platelet agonist highly expressed in atherosclerotic plaques. Circ Res 86: 131-138, 2000.

49. Schober A, Knarren S, Lietz M, Lin EA and Weber C: Crucial role of stromal cell-derived factor-1alpha in neointima formation after vascular injury in apolipoprotein E-deficient mice. Circulation 108: 2491-2497, 2003.

50. Petersen F, Bock L, Flad HD and Brandt E: Platelet factor 4induced neutrophil-endothelial cell interaction: involvement of mechanisms and functional consequences different from those elicited by interleukin-8. Blood 94: 4020-4028, 1999.

51. Engstad CS, Lia K, Rekdal O, Olsen JO and Osterud B: A novel biological effect of platelet factor 4 (PF4): enhancement of LPSinduced tissue factor activity in monocytes. J Leukoc Biol 58: 575-581, 1995.

52. Pitsilos S, Hunt J, Mohler ER, Prabhakar AM, Poncz M, Dawicki J, Khalapyan TZ, Wolfe ML, Fairman R, Mitchell M, Carpenter J, Golden MA, Cines DB and Sachais BS: Platelet factor 4 localization in carotid atherosclerotic plaques: correlation with clinical parameters. Thromb Haemost 90: 1112-1120, 2003.
53. Yu G, Rux AH, Ma P, Bdeir K and Sachais BS: Endothelial expression of E-selectin is induced by the platelet-specific chemokine platelet factor 4 through LRP in an NF-kappaBdependent manner. Blood 105: 3545-3551, 2005.

54. Nassar T, Sachais BS, Akkawi S, Kowalska MA, Bdeir K, Leitersdorf E, Hiss E, Ziporen L, Aviram M, Cines D, Poncz M and Higazi AA: Platelet factor 4 enhances the binding of oxidized low-density lipoprotein to vascular wall cells. J Biol Chem 278: 6187-6193, 2003 .

55. Imai $\mathrm{T}$, Hieshima K, Haskell C, Baba M, Nagira M, Nishimura M, Kakizaki M, Takagi S, Nomiyama H, Schall TJ and Yoshie O: Identification and molecular characterization of fractalkine receptor CX3CR1, which mediates both leukocyte migration and adhesion. Cell 91: 521-530, 1997.

56. Bazan JF, Bacon KB, Hardiman G, Wang W, Soo K, Rossi D, Greaves DR, Zlotnik A and Schall TJ: A new class of membranebound chemokine with a CX3C motif. Nature 385: 640-644, 1997.

57. Wong BW, Wong D and McManus BM: Characterization of fractalkine (CX3CL1) and CX3CR1 in human coronary arteries with native atherosclerosis, diabetes mellitus, and transplant vascular disease. Cardiovasc Pathol 11: 332-338, 2002.

58. Lucas AD, Bursill C, Guzik TJ, Sadowski J, Channon KM and Greaves DR: Smooth muscle cells in human atherosclerotic plaques express the fractalkine receptor CX3CR1 and undergo chemotaxis to the CX3C chemokine fractalkine (CX3CL1). Circulation 108: 2498-2504, 2003.

59. Combadiere C, Potteaux S, Gao JL, Esposito B, Casanova S, Lee EJ, Debre P, Tedgui A, Murphy PM and Mallat Z: Decreased atherosclerotic lesion formation in CX3CR1/ apolipoprotein E double knockout mice. Circulation 107: 1009-1016, 2003.

60. Schafer A, Schulz C, Eigenthaler M, Fraccarollo D, Kobsar A, Gawaz M, Ertl G, Walter U and Bauersachs J: Novel role of the membrane-bound chemokine fractalkine in platelet activation and adhesion. Blood 103: 407-412, 2004.

61. Faure S, Meyer L, Costagliola D, Vaneensberghe C, Genin E, Autran B, Delfraissy JF, McDermott DH, Murphy PM, Debre P, Theodorou I and Combadiere C: Rapid progression to AIDS in HIV+ individuals with a structural variant of the chemokine receptor CX3CR1. Science 287: 2274-2277, 2000.

62. Moatti D, Faure S, Fumeron F, Amara Mel-W, Seknadji P, McDermott DH, Debre P, Aumont MC, Murphy PM, de Prost D and Combadiere C: Polymorphism in the fractalkine receptor CX3CR1 as a genetic risk factor for coronary artery disease. Blood 97: 1925-1928, 2001.

63. McDermott DH, Halcox JP, Schenke WH, Waclawiw MA, Merrell MN, Epstein N, Quyyumi AA and Murphy PM: Association between polymorphism in the chemokine receptor CX3CR1 and coronary vascular endothelial dysfunction and atherosclerosis. Circ Res 89: 401-407, 2001

64. McDermott DH, Fong AM, Yang Q, Sechler JM, Cupples LA, Merrell MN, Wilson PW, D'Agostino RB, O'Donnell CJ, Patel DD and Murphy PM: Chemokine receptor mutant CX3CR1-M280 has impaired adhesive function and correlates with protection from cardiovascular disease in humans. J Clin Invest 111: 1241-1250, 2003.

65. Stievano L, Piovan E and Amadori A: C and CX3C chemokines: cell sources and physiopathological implications. Crit Rev Immunol 24: 205-228, 2004.

66. Third Joint Task Force of European and other Societies on Cardiovascular Disease Prevention in Clinical Practice: European quidelines on cardiovascular disease prevention in clinical practice. Eur J Cardiovasc Prev R 10: 1-78, 2003.

67. Deo R, Khera A, McGuire DK, Murphy SA, Meo Neto Jde P, Morrow DA and de Lemos JA: Association among plasma levels of monocyte chemoattractant protein-1, traditional cardiovascular risk factors, and subclinical atherosclerosis. J Am Coll Cardiol 44: 1812-1818, 2004.

68. Hoogeveen RC, Morrison A, Boerwinkle E, Miles JS, Rhodes CE, Sharrett AR and Ballantyne CM: Plasma MCP-1 level and risk for peripheral arterial disease and incident coronary heart disease: Atherosclerosis Risk in Communities study. Atherosclerosis 183: 301-307, 2005.

69. De Lemos JA, Morrow DA, Sabatine MS, Murphy SA, Gibson CM, Antman EM, McCabe CH, Cannon CP and Braunwald E: Association between plasma levels of monocyte chemoattractant protein-1 and long-term clinical outcomes in patients with acute coronary syndromes. Circulation 107: 690-695, 2003. 
70. Romuk E, Skrzep-Poloczek B, Wojciechowska C, Tomasik A, Birkner E, Wodniecki J, Gabrylewicz B, Ochala A and Tendera M: Selectin-P and interleukin-8 plasma levels in coronary heart disease patients. Eur J Clin Invest 32: 657-661, 2002.

71. Troseid M, Lappegard KT, Claudi T, Damas JK, Morkrid L, Brendberg R and Mollnes TE: Exercise reduces plasma levels of the chemokines MCP-1 and IL-8 in subjects with the metabolic syndrome. Eur Heart J 25: 349-355, 2004.

72. Ghilardi G, Biondi M, Turri O, Guagnellini E and Scorza R: Internal carotid occlusive disease and polymorphisms of fractalkine receptor CX3CR1: a genetic risk factor. Stroke 35: 1276-1279, 2004.

73. Pease JE and Horuk R: CCR1 antagonists in clinical development. Expert Opin Investig Drugs 4: 785-796, 2005.

74. Charo IF and Taubman MB: Chemokines in the pathogenesis of vascular disease. Circ Res 95: 858-866, 2004.

75. Usui M, Egashira K, Ohtani K, Kataoka C, Ishibashi M, Hiasa K, Katoh M, Zhao Q, Kitamoto S and Takeshita A: Anti-monocyte chemoattractant protein-1 gene therapy inhibits restenotic changes (neointimal hyperplasia) after balloon injury in rats and monkeys. FASEB J 16: 1838-1840, 2002.
76. Schmeisser A, Soehnlein O, Illmer T, Lorenz HM, Eskafi S, Roerick O, Gabler C, Strasser R, Daniel WG and Garlichs CD: ACE inhibition lowers angiotensin II-induced chemokine expression by reduction of NF-kappaB activity and AT1 receptor expression. Biochem Biophys Res Commun 325: 532540,2004

77. Fliser D, Buchholz K and Haller H: EUropean Trial on Olmesartan and Pravastatin in Inflammation and Atherosclerosis (EUTOPIA) investigators. Antiinflammatory effects of angio-tensin II subtype 1 receptor blockade in hypertensive patients with microinflammation. Circulation 110: 1103-1107, 2004.

78. Di Gregorio GB, Yao-Borengasser A, Rasouli N, Varma V, Lu T, Miles LM, Ranganathan G, Peterson CA, McGehee RE and Kern PA: Expression of CD68 and macrophage chemoattractant protein-1 genes in human adipose and muscle tissues: association with cytokine expression, insulin resistance, and reduction by pioglitazone. Diabetes 54: 2305-2313, 2005. 